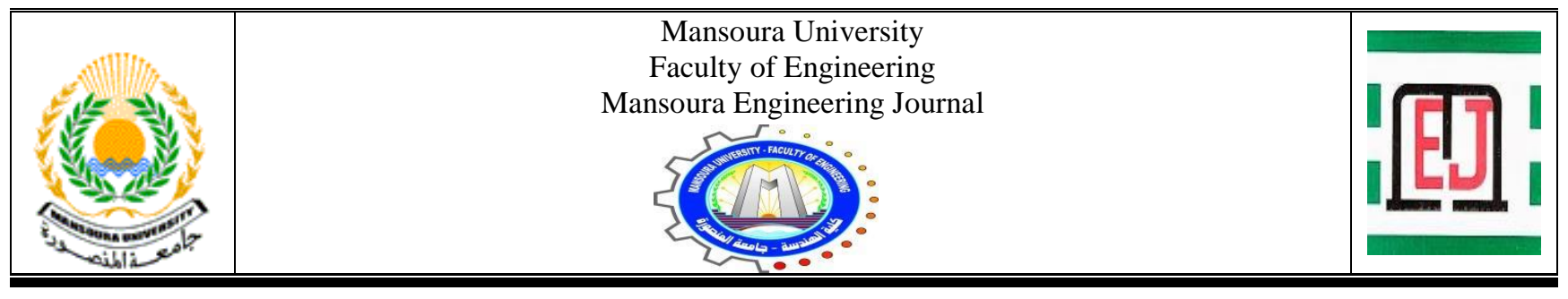

\title{
Flexible Pavement maintenance Based on Calibrated Performance Curve
}

\author{
Essam Baheeg Ahmed*, Hassan Abd-elzaher Mahdy and Hamdy Elsayed Mohamed
}

\begin{tabular}{|l|}
\hline KEYWORDS: \\
Benkelman \\
Beam(BBD), \\
Performance curve, \\
prediction model, \\
pavement condition \\
index(PCI), Paver, \\
Structure Number $(\mathrm{SN})$ \\
\\
\hline
\end{tabular}

\begin{abstract}
In this paper, a performance curve is used to optimize flexible pavement maintenance. The main aim of this study is to develop a performance model based on Benkelman Beam (BB) results by using prediction models derived from the data for Pavement Condition Index (PCI) that was obtained from three districts belonging to the General Authority for Roads, Bridges and Land Transport (GARBLT) which consist of about Central district (26sections), Middle-Delta (22 sections), and East-Delta (14 sections) with a total length of 124 Kilometers. The proposed model was validated by comparing the predicted values with actual (PCI) with a coefficient of determination $\mathbf{R}^{\wedge} 2$ () equals 0.87 . Structural evaluation of in-service pavements is a key activity for both the project and network-level pavement management systems. Benkelman Beam was used for measuring the deflection. Test points were taken at a distance of 1.5 $m$ from the edge of the pavement. Since the deflections measured by the Benkelman Beam are influenced by the pavement temperature and seasonal variations in climate, therefore, pavement was recorded temperature for making subsequent corrections to the deflection values. Since the Structure Number (SN) evaluation of in-service pavements is a key component for both the Structural Condition Index (SCI), the resulting deflections from (BB) were converted to structural number (SN) using a model and the validity has been checked by taking samples from the pavement layers, which revealed a strong correlation between them with a coefficient of determination $\left(R^{\wedge} 2\right)$ of 0.62 . The structure number in $\mathbf{2 0 1 8}$ is predicted from the proposed model and then compared with actual field measurements for the same year. A conclusion is made regarding the validity of the proposed prediction model with a coefficient of determination $\left(R^{\wedge} 2\right)$ equals 0.91. Since (BB) reading is important to determine Pavement Condition Index (PCI) value.
\end{abstract}

Received: (08 March, 2021) - Revised: (04 April, 2021) - Accepted: (19 April, 2021)

*Corresponding Author: Essam Baheeg Ahmed Mahmoud, M.sc Student, Civil Engineering, Public Works Department, Faculty of Engineering, Ain Shams University, Egypt. (E-mail: essambaheeg.pg2017@gmail.com)

Hassan Abd-elzaher Hassan Mahdy, Professor. of Highway and Airport Engineering, Public Works Department, Faculty of Engineering, Ain Shams University, Egypt. (E-mail: Drhassanmahdy@gmail.com).

Hamdy Elsayed Mohamed, Professor of Highway and Airport Engineering, Public Works Department, Faculty of Engineering, Ain Shams University, Egypt. (E-mail: hamdyibrahim100@yahoo.com).

\section{INTRODUCTION AND BACKGROUND}

$\mathrm{T}$

THE Egyptian road consists of about 188,200 kilometers, 179,900 kilometers paved roads $(95,6 \%)$ and 8,300 kilometers unpaved by $(4,4 \%)$. The road network under the (GARBLT) consists of about 28,100 kilometers of paved roads [1]. Table (1) lists the increase in the length of the road network under (GARBLT) in the last 7 years. 
TABLE (1)

TOTAL LENGTH OF PAVED ROAD NETWORK ROAD NETWORK UNDER THE (GARBLT)

\begin{tabular}{l||c||c||c||c||c||c||c||c||c||} 
Year & $2017 / 2018$ & $2016 / 2017$ & $2015 / 2016$ & $2014 / 2015$ & $2016 / 2014$ & $2012 / 2013$ & $2011 / 2012$ \\
\hline Item & 28120 & 27480 & 27321 & 25050 & 24700 & 23781
\end{tabular}

TABLE (2)

LIST THE STUDY LINKS

\begin{tabular}{|c|c|c|c|c|c|c|c|}
\hline Road ID & Link Name & Governorate & $\begin{array}{l}\text { Length } \\
\text { (Km) }\end{array}$ & $\begin{array}{l}\text { No. of } \\
\text { section }\end{array}$ & Width & AADT & SN \\
\hline 1 & Mustorod-Izbt bata & Qalubia & 22 & 11 & 7.5 & 8997 & 4.66 \\
\hline 2 & Izbt bata- Mustorod & Qalubia & 22 & 11 & 7.5 & 7519 & 4.66 \\
\hline 3 & Mansoura-Aga & Dakahlia & 14 & 7 & 7.5 & 15774 & 5.31 \\
\hline 4 & Aga- Mansoura & Dakahlia & 14 & 7 & 7.5 & 15898 & 5.31 \\
\hline 5 & Hykesteb - Belbaes & Cairo & 26 & 13 & 7.5 & 7779 & 3.8 \\
\hline 6 & Belbaes - Hykesteb & Cairo & 26 & 13 & 7.5 & 7998 & 3.8 \\
\hline
\end{tabular}

Based on the suggested methodology (Predict model of the road deterioration based on soil properties and pavement section, Evaluate the structural and functional parameters of the selected road to get the actual pavement condition index in the current time, Comparison of the pavement condition index resulting from the overall pavement assessments in the current time with the pavement condition index resulting from the Predict model for the same year), the network was divided into homogeneous links and each link has the same characteristics regarding the following factors:

1) Roadway components (pavement width and road length).

2) Traffic volume.

3) Pavement layers thicknesses and types

Table (2) lists the study links of roads

Traffic volume is increasing in the last year, which affects the pavement performance curve [2].

Distress and structure are the most important components of the pavement design, rehabilitation, and management. Accurate pavement assessment is responsible for the majority of the cost-effective maintenance and rehabilitation strategies built using the pavement management system (PMS) [3].

Performance models are required in two distinct contexts depending on the pavement management level involved. Managing a pavement network effectively requires decisions at two-level (1) the network level, in which the agency's entire pavement network is considered for budgeting, planning, scheduling, and selection of potential M\&R projects and (2) the project level, in which potential projects are evaluated in more detail to identify feasible alternatives that address the site-specific conditions. At the project level, fairly detailed and specific models are required for predicting the performance expected for an individual pavement section. It is used in the life cycle cost analysis of pavement sections. At the network level, general average prediction models are required to provide estimates of expected performance for atypical pavement or class of pavement. It is used in preparing long-term budget estimates of the cost to maintain the highway system at a specified minimum performance level or determines the consequences of future funding level [4][5][6].
Delays in pavement repairs generally lead to increased severity of defects and higher maintenance costs.

Delay of maintenance and rehabilitation can increase the life cycle cost of providing a good level of pavement performance and may mean that year later the entire pavement will have to be rebuilt. Much research effort has been devoted recently to the study and develop of pavement performance and condition, However, this research will study functional and structural evaluation as well [7][8][9]. The existing pavement performance prediction models can be classified into six categories: empirical models for pavement sections, empirical models for pavement families, probabilistic models, mechanistic models, nondestructive test prediction models, and distress prediction models [10][1'].

A thorough review is conducted on various categories of performance prediction models in paper to evaluate their relative merits and to identify the factors that have a significant effect on pavement performance. Based on identified variables in the previous step, data are collected from the field as well as from the proper sources and the collected data are checked, screened, modified if necessary, and classified into the mains group for analysis. Preliminary analysis is performed as needed for this stage. The field investigation of this study is divided into two parts: (1) The first part consists of pavement performance measures to study the variability in collected performance ratings. (2) The second part of the study involves the model validation data, on 29 sections (about 124 kilometers). Several problems are encountered during the data collection and field measurements. Sufficient data are collected from several sections having different condition ratings. Each section is investigated by five observers, having different experience levels in pavement condition rating. A thorough analysis is performed on the collected data identified the significance difference due to the level of experience in various condition ratings, analysis and mount of variation in different performance ranges[ $\left.{ }^{Y}\right]\left[1^{r}\right][1 \leqslant]$. The collected data is analyzed. Using PAVER and SPSS statistical package [10] . Attempts are made to collect additional data to check the 
validity of the recommended model. The pavement performance in 2018 is predicted from the proposed model and then compared with actual field measurements for the same year. A conclusion is made regarding the validity of the proposed prediction model [1'].

\section{DATA ELEMENTS}

The most significant variables affecting the rate of deterioration of pavement performance include pavement construction dates, pavement layers material types, pavement layer thickness, current traffic, and surrounding area type. Therefore data were collected and grouped into five general categories representing the following:

1) Pavement performance records.

2) Pavement construction or last overlay data (pavement age).

3) Traffic volume.

4) Pavement layers thicknesses and types.

5) Surface deflection/Benkelman beam deflection.

\section{A. Pavement performance date}

Pavement Condition Index (PCI) values were obtained from links road history files in (GARBLT) for each of the 3 districts. The investigated sections were sorted in descending order according to the average PCI value of the section. The pavement age of any section is the time since the last construction reconstruction date of that section. Most of Cairo, Dakahlia, and Qalubia links were maintained during the last 5 years and, therefore, the maximum age of these links in the 2018 survey was 6 years and recorded on 6 links. The age of each section was carefully determined by the use of the EastDelta District road history file. Table (3) shows the PCI values for the segments on the Mustorod-IzbetBata road in one direction, based on field data collected from 2012 to 2017. Conclusions Fig. 1 portrays the PCI values for all sections in 2012. Fig 2, 3 are shown the PCI values on the MustorodIzbetBata road in two directions from 2013 to 2017.

TABLE (3)

PCI VALUES FOR THE SEGMENTS ON THE MUSTORODIZBETBATA ROAD IN ONE DIRECTION

\begin{tabular}{|c|c|c|c|c|c|c|}
\hline 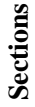 & 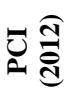 & ป气 & ప્ & 己ั & చั & ซู \\
\hline 1 & 91 & 89 & 85 & 84 & 80 & 79 \\
\hline \multirow{4}{*}{2} & 60 & 56 & 53 & 50 & 49 & 47 \\
\hline & 43 & 41 & 30 & 28 & 27 & 24 \\
\hline & 45 & 42 & 38 & 33 & 32 & 29 \\
\hline & 40 & 37 & 28 & 20 & 19 & 17 \\
\hline \multirow{3}{*}{3} & 75 & 71 & 70 & 64 & 63 & 59 \\
\hline & 92 & 92 & 90 & 89 & 85 & 84 \\
\hline & 83 & 81 & 76 & 74 & 71 & 64 \\
\hline 4 & 57 & 55 & 52 & 51 & 45 & 44 \\
\hline \multirow{2}{*}{5} & 93 & 93 & 92 & 91 & 87 & 83 \\
\hline & 96 & 95 & 95 & 94 & 90 & 86 \\
\hline
\end{tabular}

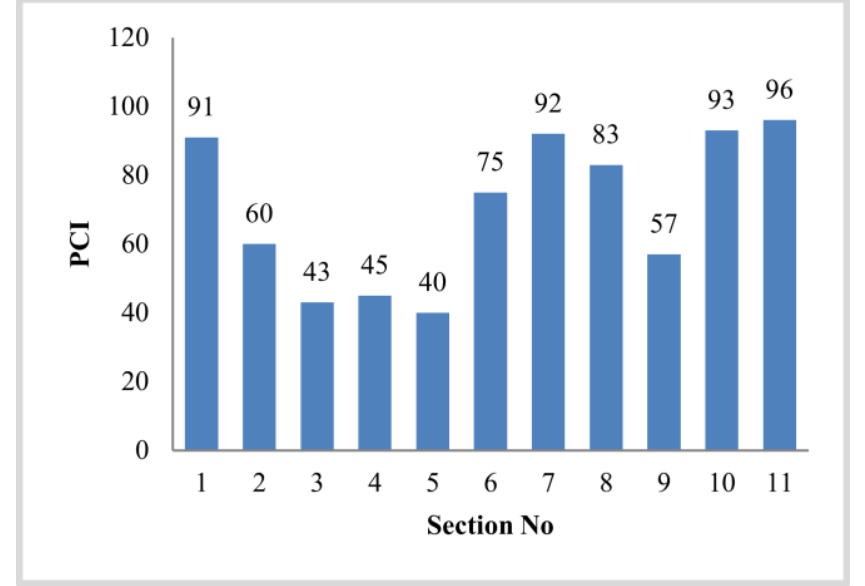

Fig.1.The PCI values of all sections at 2012

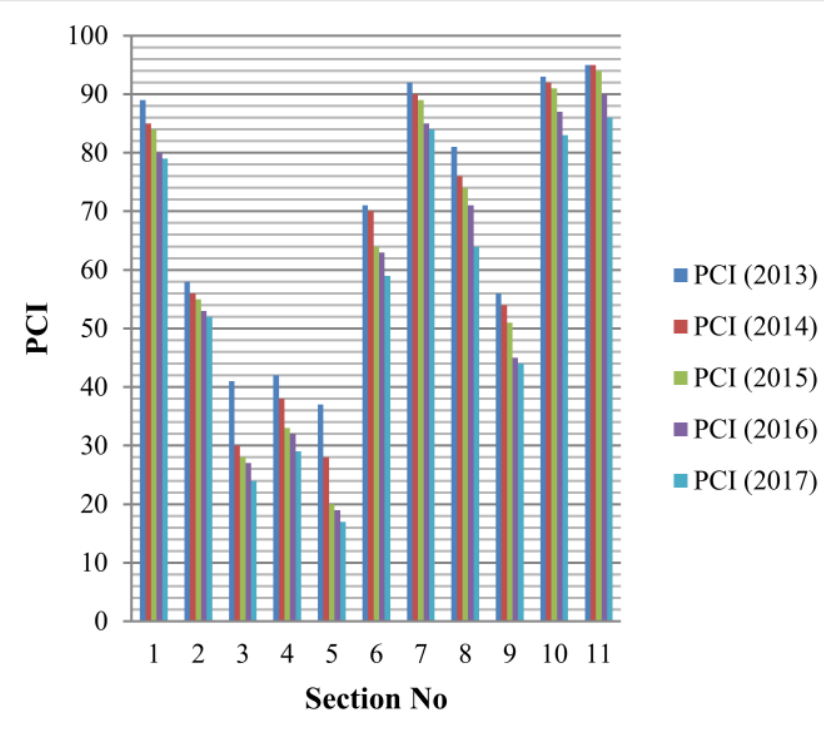

Fig.2.The PCI values of all sections from 2013 to 2017 for road 1

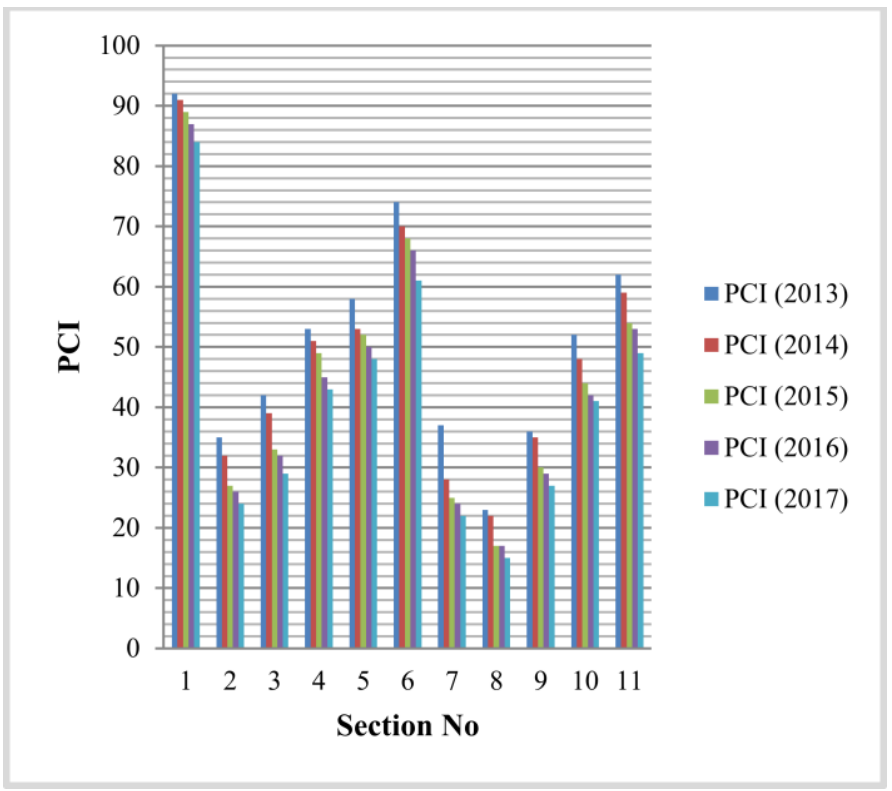

Fig.3. The PCI values of all sections from 2013 to 2017 for road 2 


\section{a. Homogeneous sections}

This analytical procedure, when the variable $\mathrm{Zc}$ (defined as the difference between the area under the response curve at any distance and the total area developed from the overall project average response at the same distance) is plotted as a function of distance along the project, unit boundaries occur at the same distance[18]. (Zx) is simply the difference in cumulative area values between the real and project average lines at a given x, as shown in Fig.4, 5 Fig.4, 5 is the product of plotting the $\mathrm{Zx}$ value against the size, $\mathrm{x}$. The position of unit boundaries often coincides with the location (along $\mathrm{x}$ ) where the slope of the Zx function changes algebraic signs, as seen in this map (ie, from negative to positive or vice versa) This basic definition serves as the ultimate foundation for determining the position of the research units' boundaries analytically[18]. Actual results are shown for an analysis unit delineation based upon pavement condition index. Results are shown in Table $(4,5)$ and illustrated in Fig. 4,5 based on field data collected from 2012 to 2017 for the segments on the Mustorod-IzbetBata road in two direction.

TABLE (4)

PCI VALUE AFTER DIVIDING ROAD 1 INTO HOMOGENEOUS SECTIONS

\begin{tabular}{|c|c|c|c|c|c|c|}
\hline 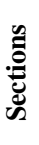 & 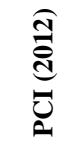 & $\underset{0}{\stackrel{0}{0}}$ & 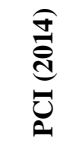 & $\begin{array}{l}\underset{0}{0} \\
0 \\
0 \\
0\end{array}$ & $\begin{array}{l}\underset{0}{0} \\
\overrightarrow{0} \\
0 \\
0\end{array}$ & 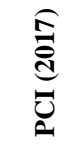 \\
\hline 1 & 91 & 89 & 85 & 84 & 80 & 79 \\
\hline 2 & 47 & 44 & 37.25 & 32.75 & 31.75 & 29.25 \\
\hline 3 & 83.33 & 81.33 & 78.6 & 75.6 & 73 & 69 \\
\hline 4 & 57 & 55 & 52 & 51 & 45 & 44 \\
\hline 5 & 94.5 & 94 & 93.5 & 92.5 & 88.5 & 84.5 \\
\hline
\end{tabular}

TABLE (5)

PCI VALUE AFTER DIVIDING ROAD 2 INTO HOMOGENEOUS SECTIONS

\begin{tabular}{|c|c|c|c|c|c|c|}
\hline : & అ & అల్తి & అ & అ & పี & ฮิ \\
\hline 1 & 93 & 92 & 91 & 89 & 87 & 84 \\
\hline 2 & 43 & 38.5 & 35.5 & 30 & 29 & 26.5 \\
\hline 3 & 65 & 61.66 & 58 & 56.33 & 53.66 & 50.6 \\
\hline 4 & 35 & 32 & 28.33 & 24 & 23.33 & 21.33 \\
\hline 5 & 60.5 & 57 & 53.5 & 49 & 47.5 & 45 \\
\hline
\end{tabular}

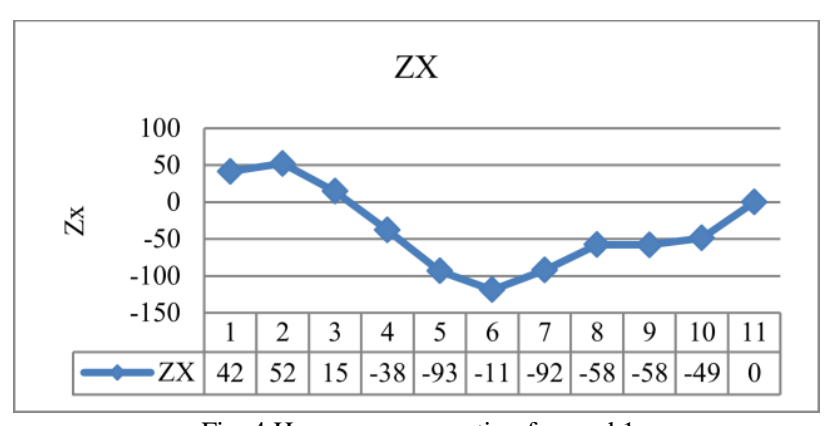

Fig. 4.Homogeneous section for road 1

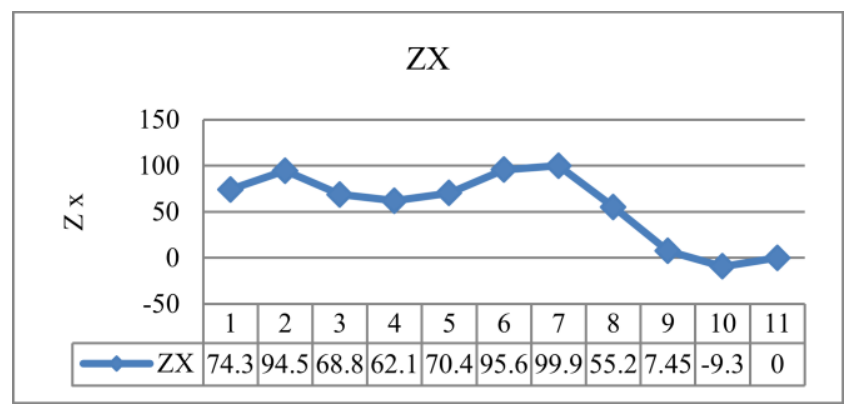

Fig.5.Homogeneous section for road 2

\section{A. Traffic volume date}

Traffic volumes considered in this study are the 2012 volumes, provided by Transportation on Egyptian Roads Network Study, in terms of average annual daily traffic (AADT), and the volumes for the years 2012 and 2017 are shown in Table(6). Fig. 6 Illustrate the network maps for all roads.

According to Table (6), age is a significant factor in estimating accumulated traffic volumes over the life cycle period. Traffic volume derived from the data for (AADT) that was obtained from Links road history files and Personal conversation with experienced engineers belonging to the General Authority for Roads, Bridges and Land Transport (GARBLT).

TABLE (6)

\begin{tabular}{|c|c|c|c|c|c|c|c|}
\hline \multirow[b]{2}{*}{ z } & \multicolumn{7}{|c|}{ THE VOLUMES FOR THE YEARS 2012 AND 2017} \\
\hline & 兰节 & 䒽 & 䢓 & 宅胥 & 宅突 & 逭㝓 & 这突 \\
\hline 1 & Mustorod Izbt bata & 8997 & 8915 & 9389 & 9667 & 9818 & 9957 \\
\hline 2 & Izbt bata Mustorod & 7519 & 7538 & 7791 & 7805 & 7980 & 8161 \\
\hline 3 & Mansoura Aga & 15774 & 15101 & 17447 & 16297 & 15608 & 15932 \\
\hline 4 & Aga Mansoura & 15898 & 16736 & 15898 & 16734 & 16224 & 16565 \\
\hline 5 & Hykesteb Belbaes & 7779 & 7934 & 8093 & 8255 & 8420 & 8588 \\
\hline 6 & Belbaes Hykesteb & 7998 & 8179 & 8343 & 8509 & 8680 & 8853 \\
\hline
\end{tabular}




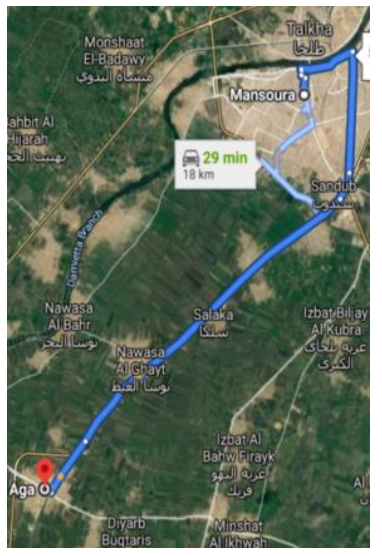

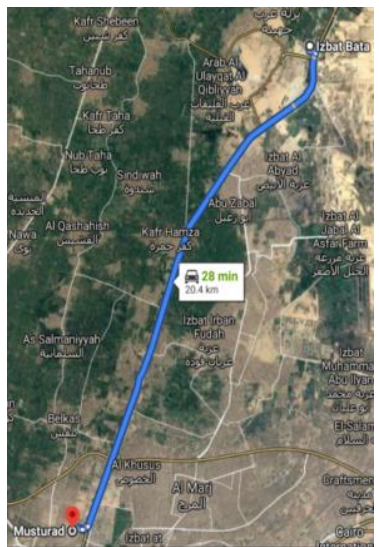

Fig. 6 Illustrate the network maps

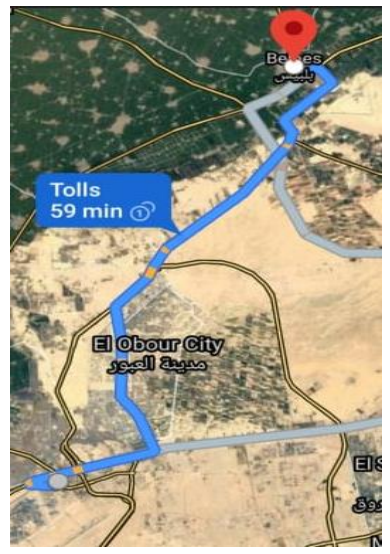

\section{DETERIORATION PREDICTION MODEL}

Table (7) presents the relation between average PCI values for the segments in each road and time based on data collected from the field. By doing least squares regression analysis for the collected data, it was found that a typical deterioration model is represented by a quadratic function in time with the dependent variable, being the PCI at a given time [16].

The deterioration model can be expressed in the following mathematical form:

$P C I=a A^{2}+b A+c$

Where:

$\boldsymbol{P C I}=$ Pavement Condition Index at time A

$\boldsymbol{A}=$ Time

$\boldsymbol{a}, \boldsymbol{b}, \boldsymbol{c}=$ unknown coefficients

Based on the data illustrated in Table (7), values of PCI are plotted as a function of time in Fig. 7. Fig.8. values of PCI are plotted as a function of time for section (1) road (1) is noticed from the figure that the PCI values, in general, decrease with time indicating the increase of road surface deterioration. In general, the deterioration rate is relatively slow at the beginning and then it accelerates as time increases. This finding agrees with the typical deterioration behavior of road segments.

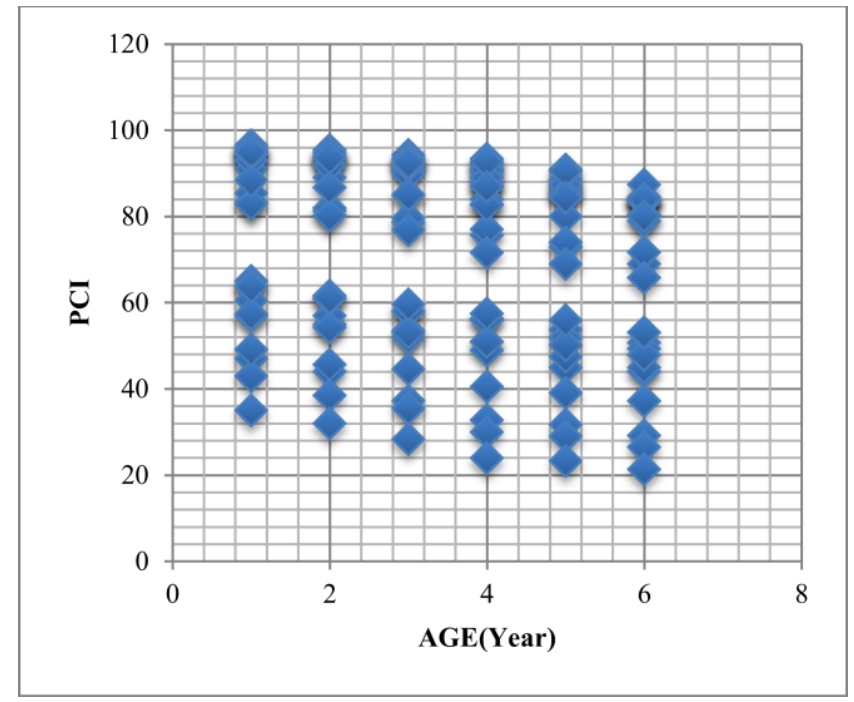

Fig.7. values of PCI are plotted as a function of time for all sections
TABLE (7)

PRESENTS THE RELATION BETWEEN AVERAGE PCI VALUES FOR THE SEGMENTS IN EACH ROAD AND TIME

\begin{tabular}{|c|c|c|c|c|c|c|c|}
\hline \\
\hline \multicolumn{4}{|c|}{$\operatorname{Road}(1)$} & \multicolumn{4}{|c|}{$\operatorname{Road}(2)$} \\
\hline $\begin{array}{l}\text { Section } \\
\text { No }\end{array}$ & Year & Age & PCI & $\begin{array}{l}\text { Section } \\
\text { No }\end{array}$ & Year & Age & PCI \\
\hline \multirow{6}{*}{1} & 2012 & 1 & 91 & \multirow{6}{*}{1} & 2012 & 1 & 43 \\
\hline & 2013 & 2 & 89 & & 2013 & 2 & 38.5 \\
\hline & 2014 & 3 & 85 & & 2014 & 3 & 35.5 \\
\hline & 2015 & 4 & 84 & & 2015 & 4 & 30 \\
\hline & 2016 & 5 & 80 & & 2016 & 5 & 29 \\
\hline & 2017 & 6 & 79 & & 2017 & 6 & 26.5 \\
\hline \multirow{6}{*}{2} & 2012 & 1 & 47 & \multirow{6}{*}{2} & 2012 & 1 & 65 \\
\hline & 2013 & 2 & 44 & & 2013 & 2 & 61.67 \\
\hline & 2014 & 3 & 37.25 & & 2014 & 3 & 58 \\
\hline & 2015 & 4 & 32.75 & & 2015 & 4 & 56.33 \\
\hline & 2016 & 5 & 31.75 & & 2016 & 5 & 53.67 \\
\hline & 2017 & 6 & 29.25 & & 2017 & 6 & 50.67 \\
\hline \multirow{6}{*}{3} & 2012 & 1 & 83.33 & \multirow{6}{*}{3} & 2012 & 1 & 35 \\
\hline & 2013 & 2 & 81.33 & & 2013 & 2 & 32 \\
\hline & 2014 & 3 & 78.67 & & 2014 & 3 & 28.33 \\
\hline & 2015 & 4 & 75.67 & & 2015 & 4 & 24 \\
\hline & 2016 & 5 & 73 & & 2016 & 5 & 23.33 \\
\hline & 2017 & 6 & 69 & & 2017 & 6 & 21.33 \\
\hline \multirow{6}{*}{4} & 2012 & 1 & 57 & \multirow{6}{*}{4} & 2012 & 1 & 60.5 \\
\hline & 2013 & 2 & 55 & & 2013 & 2 & 57 \\
\hline & 2014 & 3 & 52 & & 2014 & 3 & 53.5 \\
\hline & 2015 & 4 & 51 & & 2015 & 4 & 49 \\
\hline & 2016 & 5 & 45 & & 2016 & 5 & 47.5 \\
\hline & 2017 & 6 & 44 & & 2017 & 6 & 45 \\
\hline \multirow{6}{*}{5} & 2012 & 1 & 94.5 & \multirow{6}{*}{5} & 2012 & 1 & 85.33 \\
\hline & 2013 & 2 & 94 & & 2013 & 2 & 82 \\
\hline & 2014 & 3 & 93.5 & & 2014 & 3 & 79.67 \\
\hline & 2015 & 4 & 92.5 & & 2015 & 4 & 77 \\
\hline & 2016 & 5 & 88.5 & & 2016 & 5 & 74 \\
\hline & 2017 & 6 & 84.5 & & 2017 & 6 & 71.67 \\
\hline
\end{tabular}




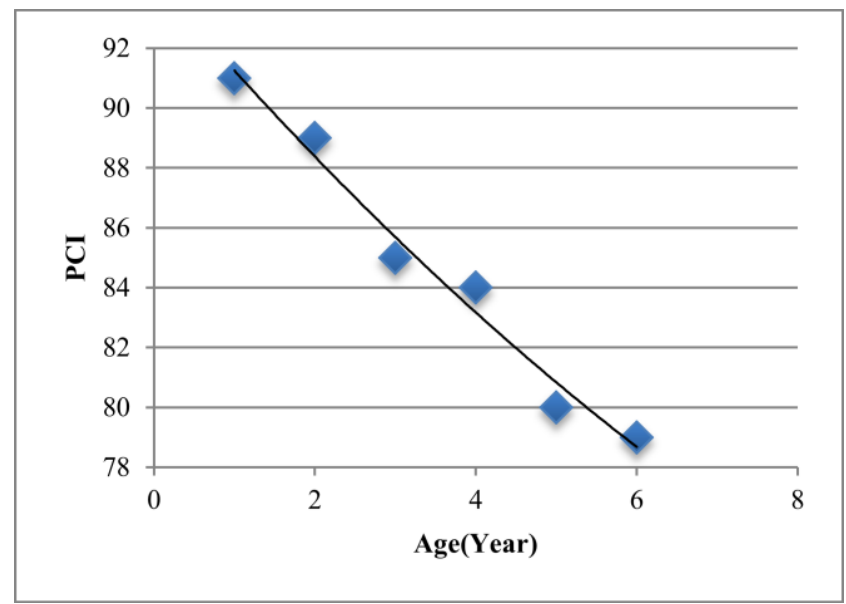

Fig.8. values of PCI are plotted as a function of time for section (1) road (1)
Applying the least squares regression equation (Equation (1)) on the models given in Table (8) where (A) is Age or time, the coefficients $a, b$, and $c$ were obtained. It can be noticed that Eqn. (1) represents the collected data reasonably well with a coefficient of determination $\left(\mathbf{R}^{2}\right)$ equals. Values of coefficients a, b, and $\mathrm{c}$ as well as the coefficient of determination $\left(\mathbf{R}^{\mathbf{2}}\right)$ are listed in Table (8).

\section{Validation of the Prediction Model}

As a further examination of the developed model, $62 \mathrm{road}$ sections were investigated to validate the proposed model. The actual, PCI values were obtained through field surveys from 3 districts: Central district (26sections), Middle-Delta (22 sections), and East-Delta (14 sections). The selected road sections were chosen to cover all pavement conditions and traffic volumes.

TABLE (8)

VALUES OF COEFFICIENTS A, B, AND C AS WELL AS THE COEFFICIENT OF DETERMINATION (R2)

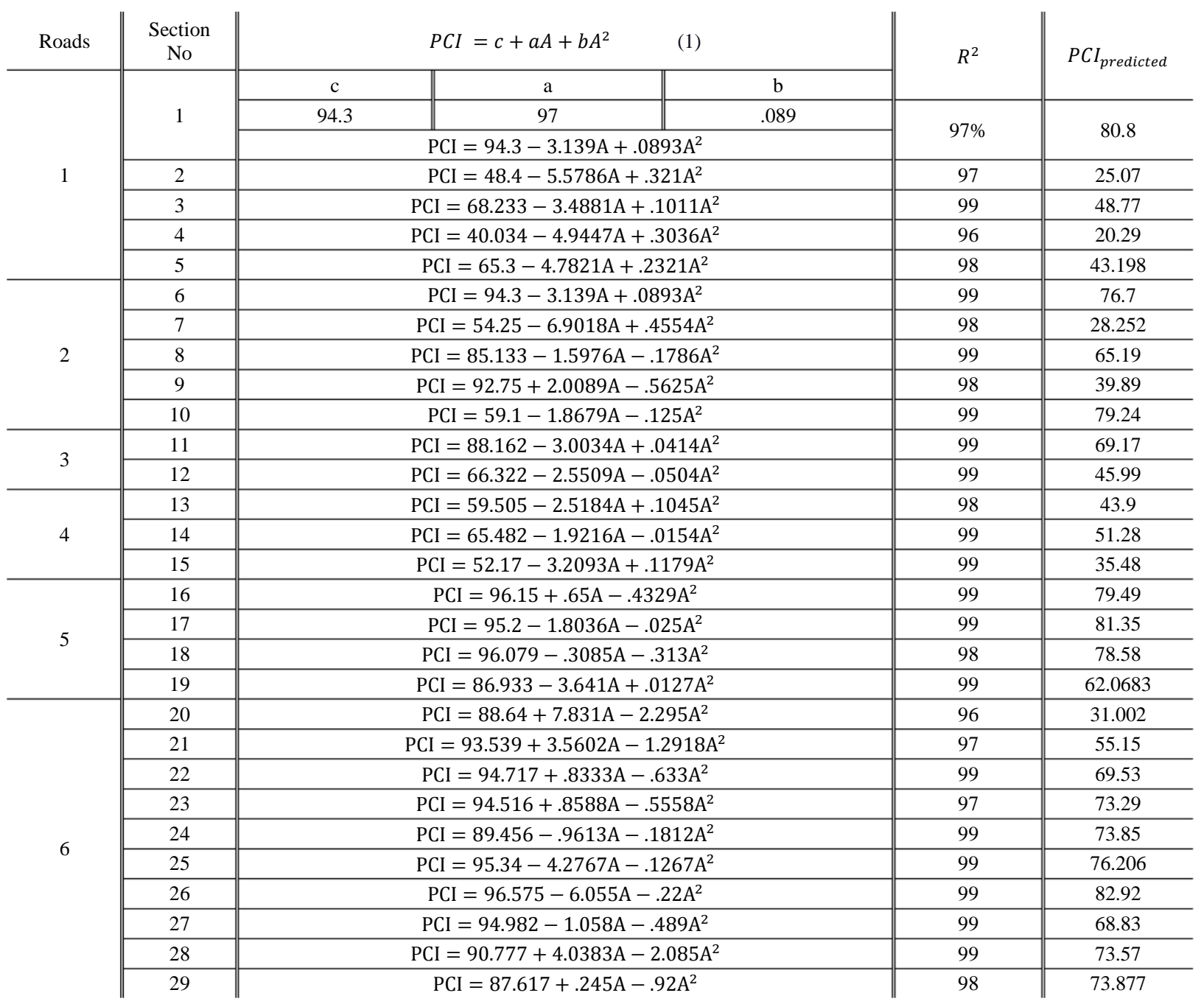




\section{VARIAbility OF PAVEMENT CONDITION INDEX MEASUREMENTS}

Information gathered was used to determine the pavement age to predict the PCI for each section. The prediction model obtained in Table (8) was utilized to estimate the corresponding PCI values in Table (8).

\section{A. Development of pavement condition distress index}

The different PCI levels to see if the results depended on the pavement condition of the surveyed section. As mentioned in my research, data for this study were collected from 6 sections having different condition ratings ranged from excellent to failed condition. Each section was investigated by 5 investigators having different experience levels in pavement condition rating.

Field measurements were used to determine the actual PCI according to the procedure described in Tables $(9,10)$.

Information gathered was used to determine the pavement age to predict the PCI for each section. The prediction model shown in Table (11) was utilized to estimate the corresponding PCI values. Then a comparison was made between field and predicted PCI values.

TABLE (9)

ACTUAL PCI OF THE SURVEYED SECTION

\begin{tabular}{|c|c|c|c|c|c|c|c|}
\hline Sec & 1 & 2 & 3 & 4 & 5 & Mean & PCI \\
\hline 2 & 80 & 79 & 80 & 80 & 79 & 79.6 & 79.6 \\
\hline 4 & 23 & 23 & 22 & 22 & 23 & 22.6 & \multirow{2}{*}{25.2} \\
\hline 6 & 28 & 27 & 28 & 28 & 28 & 27.8 & \\
\hline 8 & 42 & 42 & 41 & 42 & 42 & 41.8 & \multirow{3}{*}{49.6} \\
\hline 10 & 48 & 48 & 48 & 47 & 48 & 47.8 & \\
\hline 12 & 59 & 59 & 59 & 60 & 59 & 59.2 & \\
\hline 14 & 22 & 22 & 21 & 20 & 22 & 21.4 & \multirow{3}{*}{20.3} \\
\hline 16 & 14 & 14 & 14 & 13 & 14 & 13.8 & \\
\hline 18 & 26 & 26 & 26 & 26 & 25 & 25.8 & \\
\hline 20 & 39 & 39 & 39 & 38 & 39 & 38.8 & \multirow{2}{*}{41.9} \\
\hline 22 & 46 & 45 & 45 & 45 & 44 & 45 & \\
\hline
\end{tabular}

\section{1) Comparing Actual PCI's With Predicted Values}

To illustrate how accurate the actual PCI values fit the prediction equation values. A plot showing the actual PCI versus the predicted values is given in Fig. 9 for all verification sections. The line of equality is also shown in the plot. The plotted data indicate a strong correlation between predicted and actual PCI values, which means that the developed model can be used successfully to predict pavement performance.

Comparing the plotted values with the tolerance limits of PCI field measurements, presented in Table (11), it was found that about 2 records from a total of 29 sections are outside the tolerance limits, as shown in Fig. 7 This result means that the variation in $87 \%$ of the verification sections results, The verification sections results may be due to the variability in field measurements.
TABLE (10)

ACTUAL PCI ACCORDING TO THE PROCEDURE

\begin{tabular}{c||c||c||c}
\multicolumn{1}{c||}{ Sec No } & PCI & Sec No & PCI \\
\hline 1 & 79.6 & 16 & 80.3 \\
\hline 2 & 25.2 & 17 & 80.1 \\
\hline 3 & 49.6 & 18 & 79.65 \\
\hline 4 & 20.3 & 19 & 61 \\
\hline 5 & 41.9 & 20 & 75.4 \\
\hline 6 & 69.4 & 21 & 79.51 \\
\hline 7 & 27.51 & 22 & 81.53 \\
\hline 8 & 64.27 & 23 & 83.08 \\
\hline 9 & 42 & 24 & 68.92 \\
\hline 10 & 79.325 & 25 & 77.53 \\
\hline 11 & 68.937 & 26 & 80.68 \\
\hline 12 & 43.7375 & 27 & 74.8 \\
\hline 13 & 41.8 & 28 & 81.533 \\
\hline 14 & 48.7 & 29 & 77.46 \\
\hline 15 & 33.2 & &
\end{tabular}

TABLE (11)

ACTUAL PCI ACCORDING TO THE PROCEDURE

\begin{tabular}{|c|c|c|c|}
\hline Sec No & $P C I_{P R E D I C T}$ & $S N_{o}$ & $S N_{e f f}$ \\
\hline 1 & 80.8 & 4.66 & 3.76528 \\
\hline 2 & 25.07 & 4.66 & 1.16826 \\
\hline 3 & 48.77 & 4.66 & 2.27268 \\
\hline 4 & 20.29 & 4.66 & 0.94551 \\
\hline 5 & 43.198 & 4.66 & 2.01303 \\
\hline 6 & 76.7 & 4.66 & 3.57422 \\
\hline 7 & 28.252 & 4.66 & 1.3165432 \\
\hline 8 & 65.19 & 4.66 & 3.037854 \\
\hline 9 & 39.89 & 4.66 & 1.858874 \\
\hline 10 & 79.24 & 4.66 & 3.692584 \\
\hline 11 & 69.17 & 5.31 & 3.672927 \\
\hline 12 & 45.99 & 5.31 & 2.442069 \\
\hline 13 & 43.9 & 5.31 & 2.33109 \\
\hline 14 & 51.28 & 5.31 & 2.722968 \\
\hline 15 & 35.48 & 5.31 & 1.883988 \\
\hline 16 & 79.49 & 3.8 & 3.02062 \\
\hline 17 & 81.35 & 3.8 & 3.0913 \\
\hline 18 & 78.58 & 3.8 & 2.98604 \\
\hline 19 & 62.0683 & 3.8 & 2.3585954 \\
\hline 20 & 31.002 & 3.8 & 1.178076 \\
\hline 21 & 55.15 & 3.8 & 2.0957 \\
\hline 22 & 69.53 & 3.8 & 2.64214 \\
\hline 23 & 73.29 & 3.8 & 2.78502 \\
\hline 24 & 73.85 & 3.8 & 2.8063 \\
\hline 25 & 76.206 & 3.8 & 2.895828 \\
\hline 26 & 82.92 & 3.8 & 3.15096 \\
\hline 27 & 68.83 & 3.8 & 2.61554 \\
\hline 28 & 73.57 & 3.8 & 2.79566 \\
\hline 29 & 73.877 & 3.8 & 2.807326 \\
\hline
\end{tabular}




\section{B. Development of pavement condition structural capacity index}

The Structural Number is a variable that measures the overall strength of a pavement structure. For the determination of the structural capacity of the existing pavements, various methods are available among which Nondestructive testing (deflection) is the most credited and inexpensive. PCI have been calculated using the following Eqn. (2) $\left[1^{\vee}\right][1 \wedge]$.
$P C I=100-\left(1-\left(S N_{e f f} / S N_{0}\right)\right) * 100$

Where:

$P C I=$ Pavement Condition Index (0-100)

$S N_{\text {eff }}=$ effective pavement structure number from NonDestructive Testing Results (Benkelman Beam test).

$S N_{o}=$ original pavement structural number is determined from in-situ Destructive Testing.

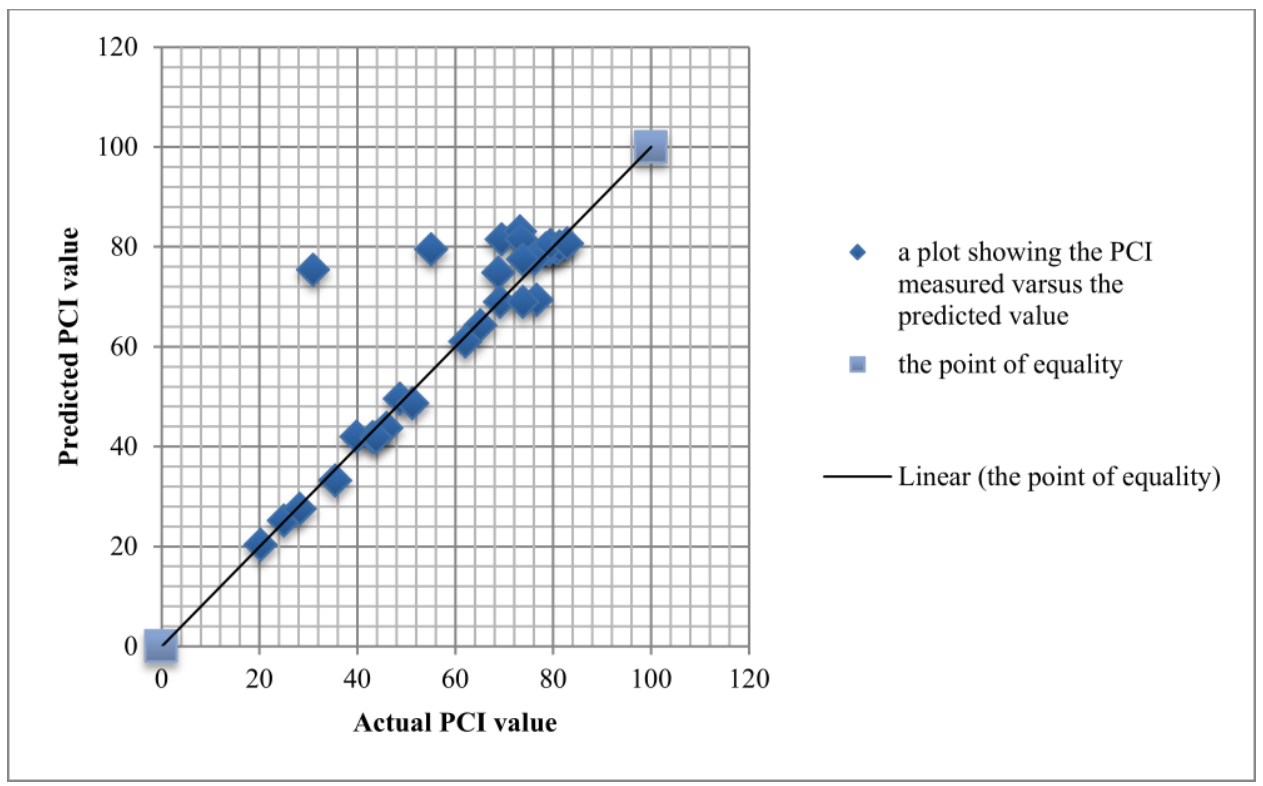

Fig.9.The actual PCI versus the predicted values (29points)

TABLE (12)

ACTUAL STRUCTURE NUMBER USING THICKNESS LAYER

\begin{tabular}{|c|c|c|c|c|c|c|c|c|c|c|c|}
\hline NO & \multicolumn{3}{|c|}{ Asphalt } & \multicolumn{4}{|c|}{ Base } & \multicolumn{4}{|c|}{ Sub base } \\
\hline \multirow{3}{*}{1} & $\begin{array}{c}\mathrm{D}_{1} \\
(\mathrm{~cm})\end{array}$ & $\begin{array}{l}\text { Stability } \\
(\mathrm{kg})\end{array}$ & $a_{1}$ & $\begin{array}{c}\mathrm{D}_{2} \\
(\mathrm{~cm})\end{array}$ & CBR & $a_{2}$ & $\mathrm{~m}_{2}$ & $\begin{array}{c}\mathrm{D}_{3} \\
(\mathrm{~cm})\end{array}$ & CBR & $a_{3}$ & $\mathrm{~m}_{3}$ \\
\hline & 10 & 875 & 0.42 & 20 & 76 & 0.13 & 1.05 & 15 & 17 & 0 & 1.05 \\
\hline & \multicolumn{11}{|c|}{$\mathrm{SN}_{0 / \text { measured }}=2.72$} \\
\hline & 10 & 735 & 0.39 & 20 & 90 & 0.14 & 1.05 & 15 & 22 & .01 & 1.05 \\
\hline
\end{tabular}

\section{1) Comparing Actual $S N$ With $S N_{\text {eff }}$ Predicted Values}

The American Association of State Highway Officials (AASHO) structural number, modified to account for subgrade support, is designated as a modified structural number using Eqn. (3)[1^].

$S N_{\mathrm{o} / \text { measured }}=a_{1} D_{1}+a_{2} D_{2} m_{2}+a_{3} D_{3} m_{3}$

Where:

$m_{2}, m_{3}=$ drainage coefficient for the layer. $a_{1}, a_{2}, a_{3}=$ layer coefficient representative of surface, base, base, and subbase courses, respectively.

$D_{1}, D_{2}, D_{3}=$ actual thickness in inches of the surface, base, and subbase courses, respectively.

Trenching and coring have been used in forensic and routine pavement evaluations to assess layers and obtain samples for laboratory testing. Trenching is a suitable alternative. After collecting samples and conducting tests, the pavement layer section data is shown in Table (12) at two sections. Table (14) displays all section records to determined SN. 


\section{- Benkelman Beam}

Benkelman Beam was used to measuring the deflection. Test points were taken at a distance of $1.5 \mathrm{~m}$ from the edge of a pavement. A standard axle load of $8162 \mathrm{~kg}$ on the rear axle of a loaded truck and tire pressure of $5.6 \mathrm{~kg} / \mathrm{cm}^{2}$ was maintained throughout. Since the deflections determined by the Benkelman Beam are affected by pavement temperature and seasonal environment fluctuations, pavement temperature, and soil subgrade data were collected at all observation points for subsequent deflection corrections.

The effective pavement structural number and the original structural number have been calculated by the following Eqn. $(3,4)$ respectively and shown in table $(12,13)$ [1 $\vee\left[1^{9}\right]$.

$S N_{\text {eff }}=3.2(\text { def })^{-.63}$

Where:

Def $=$ deflection measured by Benkelman beam in $\mathrm{mm}$

TABLE (13)

ACTUAL STRUCTURE NUMBER USING BENKELMAN BEAM

\begin{tabular}{|c|c|c|c|}
\hline$\stackrel{\vec{\Xi}}{\stackrel{0}{0}}$ & 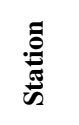 & 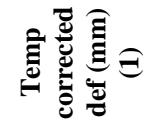 & 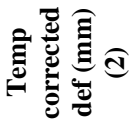 \\
\hline \multicolumn{2}{|c|}{$\begin{array}{l}\text { The actual deflection } \\
\text { when: } \\
\text { F-I }>0.025 \mathrm{~mm} \\
\mathrm{D}=2 *(\mathrm{~F}-\mathrm{S})+2.91 *(\mathrm{~F}-\mathrm{I})\end{array}$} & \multicolumn{2}{|c|}{$\begin{array}{l}\text { The actual deflection when: } \\
\text { F-I }<0.025 \mathrm{~mm} \\
\mathrm{D}=2 *(\mathrm{~F}-\mathrm{S})\end{array}$} \\
\hline 1 & 100 & 0.75 & 0.65 \\
\hline 2 & 200 & 0.63 & 0.66 \\
\hline 3 & 300 & 0.07 & 0.39 \\
\hline 4 & 400 & 0.19 & 0.11 \\
\hline 5 & 500 & 0.31 & 0.76 \\
\hline 6 & 600 & 0.7064 & 0.9573 \\
\hline 7 & 700 & 0.07 & 0.21 \\
\hline 8 & 800 & 0.71 & 0.17 \\
\hline 9 & 900 & 1.2264 & 1.2555 \\
\hline 10 & 1000 & 1.3028 & 0.7555 \\
\hline 11 & 1100 & 0.15 & 0.66 \\
\hline 12 & 1200 & 1.51 & 0.71 \\
\hline 13 & 1300 & 0.11 & 0.43 \\
\hline 14 & 1400 & 0.83 & 0.07 \\
\hline 15 & 1500 & 0.07 & 0.37 \\
\hline 16 & 1600 & 0.07 & 0.2573 \\
\hline 17 & 1700 & 0.59 & 0.13 \\
\hline 18 & 1800 & 1.15 & 0.01 \\
\hline 19 & 1900 & 0.15 & 0.6973 \\
\hline 20 & 2000 & 0.87 & 0.01 \\
\hline \multicolumn{2}{|c|}{ Mean } & 0.5732 & 0.4631 \\
\hline \multicolumn{2}{|c|}{ Std. Deviation } & 0.4669 & 0.3465 \\
\hline \multicolumn{4}{|c|}{ Final Deflection= Mean Deflection+2 Std. Deviation } \\
\hline \multicolumn{2}{|c|}{ Final Deflection } & 1.507 & 1.16 \\
\hline \multicolumn{4}{|c|}{$S N_{e f f}=3.2(\mathrm{def})^{-.63}$} \\
\hline & & 2.47 & 2.8 \\
\hline
\end{tabular}

The rebound deflection of the pavement shall be calculated in the following manner:
- Two pavement rebound indicators shall be established by subtracting(S) the intermediate (I) and Final(F) readings from the start reading:

$(\mathrm{S}-\mathrm{I})$ and $(\mathrm{S}-\mathrm{F})$

If the indicators so obtained agree within $0.025 \mathrm{~mm}$ the true rebound deflection at temperature $\mathrm{T}$ shall be calculated as: $\mathrm{D}=2 *(\mathrm{~F}-\mathrm{S})$

- If the indicators $(\mathrm{S}-\mathrm{I})$ and $(\mathrm{S}-\mathrm{F})$ differ by more than $0.025 \mathrm{~mm}$ the true rebound deflection at temperature $\mathrm{T}$ shall be calculated as:

$$
\mathrm{D}=2 *(\mathrm{~F}-\mathrm{S})+2.91 *(\mathrm{~F}-\mathrm{I})
$$

- The pavement rebound deflection at a standard temperature of $20^{\circ} \mathrm{C}$ shall be calculated from the above figure by applying the formula:

Temp corrected deflection $(\mathrm{mm})=\mathrm{D}+\mathrm{T}$

\section{2) Comparing $S N_{\text {eff }}$ With $S N$ Predicted Values}

Comparing the plotted values with the tolerance limits of SN field measurements, presented in Table (14), it was found that about 2 records from a total of 6 sections are outside the tolerance limits, as shown in Fig. 11. This result means that the variation in $62 \%$ of the verification sections result, the verification sections results may be due to the variability in field measurements.

Comparing the plotted values with the tolerance limits of SN field measurements, presented in Table $(12,13)$, it was found that about 1 records from a total of 6 sections are outside the tolerance limits, as shown in Fig. 10 This result means that the variation in $91 \%$ of the verification sections result, the verification sections results may be due to the variability in field measurements.

\section{Table (14)}

Comparing the plotted values with the tolerance limits of SN field measurements

\begin{tabular}{c||c||c||c} 
Sec No & SN $_{\text {predict }}$ & $\mathrm{SN}_{\text {eff }}$ & $\mathrm{SN}_{\text {measured }}$ \\
\hline 1 & 2.27 & 2.47 & 2.72 \\
\hline 2 & 3.03 & 2.8 & 3.3 \\
\hline 3 & 3.67 & 3.13 & 3.1 \\
\hline 4 & 2.33 & 5.51 & 4.2 \\
\hline 5 & 3.02 & 3.5 & 3.9 \\
\hline 6 & 2.80 & 2.36 & 2.8
\end{tabular}

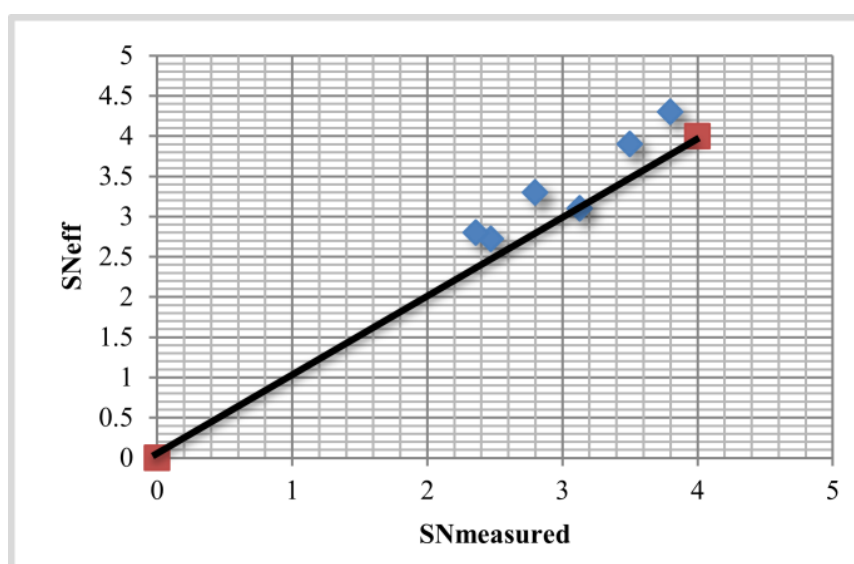

Fig.10. Comparing the plotted values with the tolerance limits of SN field measurements 


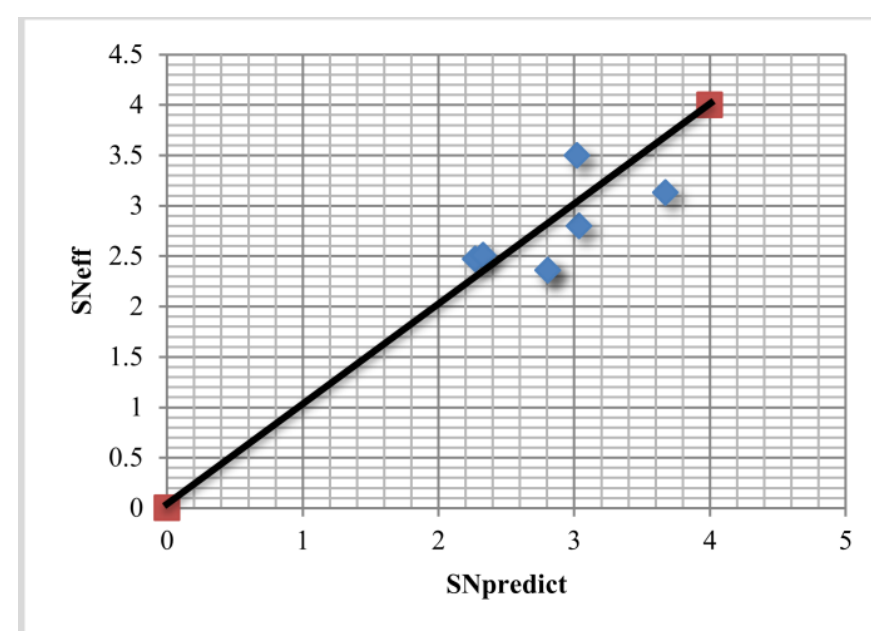

Fig.11.The actual SN using Benkelman versus the predicted values

The prediction model that was used in this research depends on two main factors to predict the pavement performance :the pavement age (years after construction or last overlay) and the pavement structural number, with age being the most important factor and the structural number being of minor importance in this study. Pavement performance prediction model has been developed based on Pavement Condition Index (PCI) as a dependent variable and the age of the pavement without structural number as the independent variables for 29 different section. Pavement age is the most significant variable in predicting pavement deterioration. In fact the data suggests that age alone can account for a substantial portion of the decline in serviceability. Pavement structural strength was found to be a crucial pavement condition indicator for changing the pavement performance and deciding the $M \& R$ strategy for selected urban pavement sections. Benkelman Beam readings are important in taking rehabilitation or reconstructed decisions due to inherent structural weaknesses, Therefore, this test can be used to filter the pavement sections that should be selected to work on the project level.

\section{AUTHORS CONTRIBUTION}

1- Conception or design of the work (50/50)

2- Data collection and tools (50/50)

3- Data analysis and interpretation (50/50)

4- Investigation $(50 / 50)$

5- Methodology (50/50)

6- Resources $(50 / 50)$

7- Software $(50 / 50)$

8- Drafting the article (50/50)

9- Final approval of the version to be published (50/50)

\section{REFERENCES}

[1] Bulletin Inventory of Roads and Bridges 2017/2018., Central Agency for Public Mobilization\&statistics., Arab Republic Of Egypt, Ref No -7214422-2018.

[2] Journal of Arab Roads, The Ministry of Transport's unique national and science experience in collaboration with Zagazig University, Third Issue, Volume 38, Arab Roads Association, Cairo, 1990.
[3] Huang, Y.H. (1993). "Pavement Analysis and Design". Prentice-Hall, Inc. a Paramount Communication Company, Englewood, New Jersy, USA.

[4] Haas, R.C.G., W.R. Hudson, and J.P. Zaniewski, "Modern Pavement Management", Krieger Publishing Company, Melbourne, Florida, 1994.

[5] Hudson, W.R., Hass, R., and Pedigo, R.D., "Pavement Management System Development". NCHRP Report 215, TRB, National Research Council Washington,d.c.,1979.

[6] Hass, R. and Hudson, W.R. "Pavement Management System", Mc Grow -Hill Book Co., New York, 1978.

[7] "Pavement Management Guide, Road, and Transportation Association" Of Canada.Oshawa.Ontario.1977.

[8] Garey, W.N., and Irick, P.I., "Pavement serviceability Performance Concept" In Transportation Research Recored250, TRB, National Research Council, Washington, D.C., 1960.

[9] Easa, S., and Kikuchi.s. "Pavement Performance Prediction Model" Report Prepared for Delaware Transportation Center, Delaware,1989.

[10] Shahin, M, Y ., and khon, S.D., "Pavement Maintenance Management For Roads And Parking Lots", Construction Engineering Research Laboratory Champain , Illinois, 1981..

[11] George, K. P., A. S. Rajagopal, and L. K. Lim. "Models for predicting pavement deterioration." Transportation Research Record 1215 (1989).

[12] Shahin, M.Y. and Walther, J.A. 1990: "Pavement Maintenance Management for Roads and Streets using the PAVER System". U.S.A. CERL Technical Report M- 90/05, Champaign, IL.

[13] Shahin, M.Y., 2005: "Pavement Management for Airports. Roads, and Parking Lots. Second edition". Springer Science Business Media, Inc., New York. NY. U.S.A.Smith, R.E.

[14] Shahin, M.Y., 1994. "Pavement Management for Airport, Roads, and Parking Lots"Chapmanan \& Hall, New York. ISBN 0-412-99201-9.

[15] U.S. Army Corps of Engineering-USACE,( 2014): Micro PAVER 6.5.7 User Manual. USA.

[16] Mahmoud, Afaf, Hassan Y. Ahmed, and Ayman M. Othman. "DETERIORATION OF EGYPTIAN DESERT ROADS IN ALMINEA DISTRICT" JES. Journal of Engineering Sciences 41.1 (2013): 21-27.

[17] Shah, Yogesh U., et al. "Development of overall pavement condition index for urban road network. "Procedia-Social and Behavioral Sciences 104 (2013): 332-341.

[18] "Transportation Officials. AASHTO Guide for Design of Pavement Structures", 1993. Vol. 1. Aashto, 1993.

[19] Thagesen, Bent, ed. "Highway and traffic engineering in developing countries”. CRC Press, 2003.

\section{Title Arabic:}

$$
\text { صيانة الرصف الأسفلتي على أساس منحنى الأداء المعاير }
$$

\section{Arabic Abstract:}

في هذه الدراسة، تم استخدام منحنى الأداء في عملية تحسين وتطوير عمليات

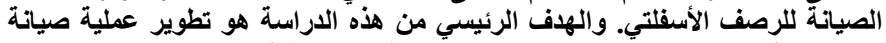

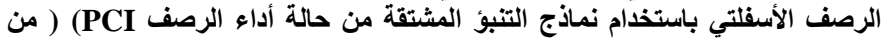

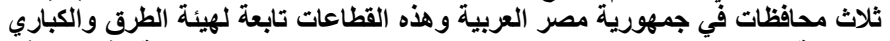

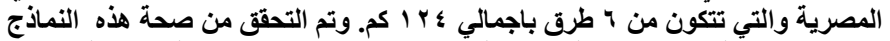

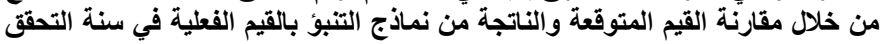

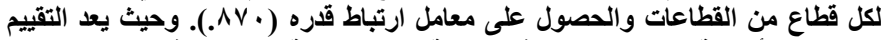

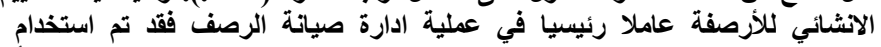

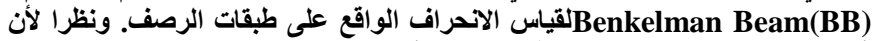

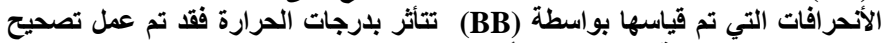

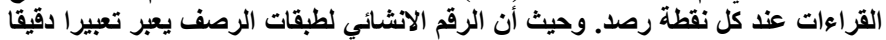

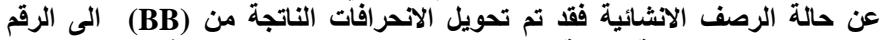

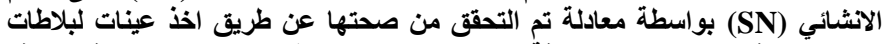

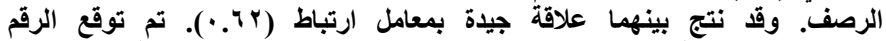

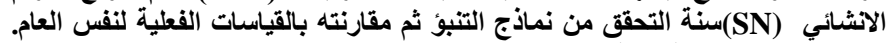

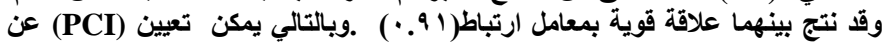
(BB). (B) 